\title{
Preference for information about shock duration in rats
}

\author{
M. R. D'AMATO and W. R. SAFARJAN \\ Rutgers University, New Brunswick, New Jersey 08903
}

\begin{abstract}
Rats were permitted to control, by means of a changeover response, the amount of time spent in either a "differentiated" or an "undifferentiated" condition. Shock occurred in both conditions on the same variable-time schedule, half of the shocks being short $(.75 \mathrm{sec})$ in duration, the other half, long $(5 \mathrm{sec})$. In the differentiated (informative) condition, all short shocks were preceded by one signal and all long shocks were preceded by a discriminatively different signal. No information about shock duration was available in the undifferentiated condition, as the same signal preceded short and long shocks. A clear and consistent preference emerged for the differentiated condition, i.e., for information about shock duration. The relevance of this finding for theories which attempt to account for the preference-for-signaled-shock phenomenon was discussed.
\end{abstract}

A number of studies have shown that, given a choice between signaled shocks and identical shocks that are unsignaled, rats frequently show a strong preference for the signaled condition (e.g., Badia \& Culbertson, 1972; Lockard, 1963; Perkins, Seymann, Levis, \& Spencer, 1966). A variety of mechanisms have been suggested to account for this preference. According to the preparatory response hypothesis, the signals enable the animal to engage in "preparatory" responses which serve to reduce the experienced aversiveness of the shocks (e.g., Perkins, 1968). The information (or uncertainty reduction) hypothesis takes the somewhat more general view that any situation that provides information about important environmental events will be preferred (largely because of uncertainty reduction) over a competing situation that contains less information about these same events (e.g., Berlyne, 1960). Finally, the safetysignal hypothesis emphasizes nonsignal periods as the source of control for the preference-for-signaledshock phenomenon. Animals prefer the signaled condition because shock never occurs during nonsignal (discriminable shock-free) periods and, as a consequence, nonsignal periods generate a much lower level of fear than is elicited by comparable nonshock periods in the unsignaled condition (e.g., Seligman \& Binik, 1977, pp. 165-180).

The validity of these competing interpretations has been the subject of a number of studies, the results of which generally confirm that discriminable shockfree periods are indeed a powerful source of control

This research, reported at the 1977 Eastern Psychological Asso. ciation Meeting in Boston, was supported by NSF Grant BNS 73-01323. Reprints may be obtained from M. R. D'Amato, Deparment of Psychology, Rutgers University, Busch Campus, New Brunswick, New Jersey 08903. in preference for signaled shock and in other phenomena as well (e.g., Badia, Harsh, Coker, \& Abbott, 1976; Hymowitz, in press; Safarjan \& D'Amato, 1978). For example, preference for the signaled condition is strongly related to the amount of discriminable shock-free time that is available in the signaled condition (Harsh \& Badia, 1976; Safarjan \& D'Amato, 1978). Moreover, rats given a choice between two signaled conditions, one containing extra signals that do not terminate in shock, show no preference for either condition (Safarjan \& D'Amato, 1977), as would be expected if their behavior were under the control of nonsignal periods rather than signals (cf. Badia et al., 1976, Experiment 1).

The present experiment addressed a simple question. Granted that information regarding nonshock periods is a strong source of behavioral control, does information about impending aversive events serve any controlling function at all; i.e., is such information reinforcing? This issue was investigated by providing certain information about the nature of the impending shock in one condition and withholding such information in a second condition. Rats were permitted to control, by means of a "changeover" response, the amount of time spent in one of two, mutually exclusive, conditions, one informative with respect to shock duration, the other uninformative. In the informative or "differentiated" condition, shocks of two different durations were randomly presented, with the shorter shock always preceded by one signal and the longer shock by a second, discriminably different signal. The same short and long shocks were delivered in the uninformative or "undifferentiated" condition; however, the signal which preceded each shock carried no information regarding shock duration. Because in both conditions 
the absence of a signal always identified a period free from shock, preference for the differentiated condition would constitute evidence that information about the nature (duration) of an impending shock can function as a reinforcer.

The only relevant published study known to us is a paper by Freeman and Badia (1975), in which rats showed no preference for a condition that supplied information regarding shock intensity. In one condition (essentially a mixed schedule of shock presentation), periods of low-intensity and high-intensity shock alternated, with no independent cues to indicate which intensity was in effect. In a second condition (a multiple schedule of shock presentation), periods of low- and high-intensity shock were identified by different visual cues. All shocks were signaled in both conditions by a 5 -sec tone stimulus. As evaluated by changeover responding, the animals did not show a preference for either condition.

Apart from the use of shock duration rather than shock intensity, the present study differs from that of Freeman and Badia mainly in that the same stimulus which, in the differentiated condition, signaled the occurrence of shock also provided information about its duration. As Freeman and Badia point out, because in their study shock intensity alternated in accordance with a variable-time 10-min schedule, it is possible there was sufficient information regarding shock intensity within the mixed schedule to inhibit the development of preference behavior. In the present study, this source of information was not available in the undifferentiated condition.

\section{METHOD}

\section{Subjects}

Eight naive female albino rats of the Sprague-Dawley strain (Madison, Wisconsin) served as subjects. The animals, which were between the ages of 90 to 120 days $(240-260 \mathrm{~g})$ at the start of the experiment, had free access to food and water and were maintained under a 12-h light-dark cycle. An experimental day normally commenced $3 \mathrm{~h}$ following onset of the light phase and ended $3 \mathrm{~h}$ before its termination. To prevent unauthorized avoidance of shock by lying on its back, each animal's back was shaved weekly.

\footnotetext{
Apparatus

The subjects were tested in one of two standard, two-lever operant chambers (Grason-Stadler, Model E 3125B-100), which were individually housed in a sound- and light-attenuating enclosure. Each chamber consisted of clear Plexiglas sidewalls, with stainless steel front and rear walls and a grid floor. A false translucent ceiling was inserted $3.0 \mathrm{~cm}$ above the levers to lower the chamber's height and thus reduce the frequency of rearing behavior. Internal dimensions, including this modification, were $23.5 \mathrm{~cm}$ in length, $27.5 \mathrm{~cm}$ in width, and $12.0 \mathrm{~cm}$ in height. The levers, which required about $.2 \mathrm{~N}$ force to operate, extended $1.7 \mathrm{~cm}$ from the front wall (or control panel) and were located $7.0 \mathrm{~cm}$ from one sidewall and $7.5 \mathrm{~cm}$ above the grid floor.

Two levels of chamber illumination were used to identify the differentiated and undifferentiated conditions. The brighter level of $5 \mathrm{fc}(54 \mathrm{~lx})$ was produced by a 10-W, 120-V ac lamp centered
}

directly above the translucent ceiling; the dimmer level of $2 \mathrm{fc}$ (22 lx) was produced by two shielded (white lens caps) $10-\mathrm{W}$ $120-\mathrm{V}$ ac stimulus lights, one located above each lever. The stimuli used as signals were white noise or a $1,000-\mathrm{Hz}$ tone, both $82 \mathrm{~dB}$ (re: $20 \mu \mathrm{N} / \mathrm{m}^{2}$ ), delivered through a $10.6-\mathrm{cm}$ speaker located below the left lever. The shock source (Grason-Stadler, Model E 1064) delivered scrambled electric shock to the front and rear walls, levers, and floor, which consisted of $.2-\mathrm{cm}$ stainless-steel bars spaced $1.3 \mathrm{~cm}$ apart (center to center). All stimulus conditions and response contingencies were controlled by a minicomputer.

\section{Procedure}

Throughout each experimental session, shocks occurred on a variable-time (VT) 1-min schedule (range, 8-305 sec) for half the subjects and on a VT 2-min schedule (range, 8-511 sec) for the other half. Both schedules were derived from a constantprobability formula (Catania \& Reynolds, 1968). Short- and longduration shocks occurred equally often in the two schedules. The short-duration shock was maintained at $.75 \mathrm{sec}$ throughout the experiment; the long shock was initially $3 \mathrm{sec}$ and subsequently increased to $5 \mathrm{sec}$ (see Figure 1). Shock intensity was increased systematically from .5 to $.8 \mathrm{~mA}$, as shown in Figures 1 and 2 . During the course of the experiment, three different shock programs were constructed for each VT schedule, the programs differing with respect to the distribution of intershock intervals and the distribution of short and long shocks.

Within each experimental session, the subjects were in one of two, mutually exclusive, signaled-shock conditions. In both conditions, all shock presentations were preceded by a 7.5-sec signal that terminated with shock onset. In the undifferentiated condition, the same signal (continuous white noise or $1,000-\mathrm{Hz}$ tone) preceded short and long shocks, thus providing information about the advent of shock but not its duration. In the differentiated condition, the 7.5-sec signal was continuous for one shock duration and pulsed (.5 sec on, $.5 \mathrm{sec}$ off) for the other; in this condition, therefore, the signal provided information about both the advent and the duration of shock. For half of the subjects, the white-noise stimulus served as the signal in the undifferentiated condition and the $1,000-\mathrm{Hz}$ tone served this function in the differentiated condition; for the other half of the subjects, this assignment was reversed. The nature of the signal (continuous or pulsed) that preceded short and long shocks was also counterbalanced across subjects.

The subjects were run every other day for a total of 108 sessions, divided into 18 six-session "phases." During each phase, half of the animals were placed in the undifferentiated condition and given the option to respond (changeover) for the other condition; the remaining animals were placed in the differentiated condition and allowed to respond for the undifferentiated condition. At the end of six sessions the conditions were reversed, so that the subjects could now respond for the signaled condition in which they had been placed during the previous phase. Two successive six-session phases, which will be referred to as an experimental "cycle," constituted an opportunity to respond for both signaled conditions. 'To facilitate forming a discrimination between the two signaled conditions, during the first experimental cycle, the undifferentiated and differentiated conditions alternated every other test session rather than every six, as in subsequent cycles; and as a precaution against excessive shock-induced suppression, shock intensity was increased gradually from .2 to $.5 \mathrm{~mA}$.

A changeover response (pressing either of the two levers) produced the alternative signaled condition for a period of $2 \mathrm{~min}$. At the end of the 2-min changeover interval, the original signaled condition was reinstated and remained in force until another changeover response occurred. Additional leverpress responses during the changeover period had no programmed consequences. For half the animals, the brighter level of chamber illumination was correlated with and served to identify the differentiated condition, whereas the dimmer level functioned as the correlated 
stimulus for the undifferentiated condition. For the remaining animals, this identification was reversed. Changeover responses that occurred during the presentation of a signal produced the correlated stimulus of the alternative signaled condition as well as the signal appropriate to that condition. Observation of the animals indicated that such responses were rare.

It is important to observe that a changeover response in no way modified the duration or the distribution of shock; changeover responses merely substituted one signaled condition for the other.

During the sixth test cycle, when the terminal shock values were reached, some subjects began to show disruptive behavioral effects of shock. In an effort to compensate for increases in "freezing" behavior that occurred during the first part of the session, starting with the seventh cycle, the session duration was extended from 100 to $200 \mathrm{~min}$. Also, to minimize the effects of shock-elicited leverpress behavior, which began to develop at this shock intensity, a 1-sec changeover delay was added, with the result that all responses emitted either during shock or during a 1-sec period following shock termination were ineffective in producing the changeover contingency.

Shock density (VT $1 \mathrm{~min}$ or $2 \mathrm{~min}$ ), nature of the correlated stimulus (bright or dim), and type of signal used in the undifferentiated condition (white noise or a $1,000-\mathrm{Hz}$ tone) were counterbalanced orthogonally. The half of the subjects for which the pulsed stimulus served to identify the short shock in the differentiated condition was determined by randomization, subject to the restriction that the white noise and tone stimuli be equally represented in the assignment. Finally, randomization determined which half of the subjects began the experiment in the undifferentiated condition.

\section{RESULTS}

The basic datum for analysis was the percentage of a session spent by each animal in changeover averaged

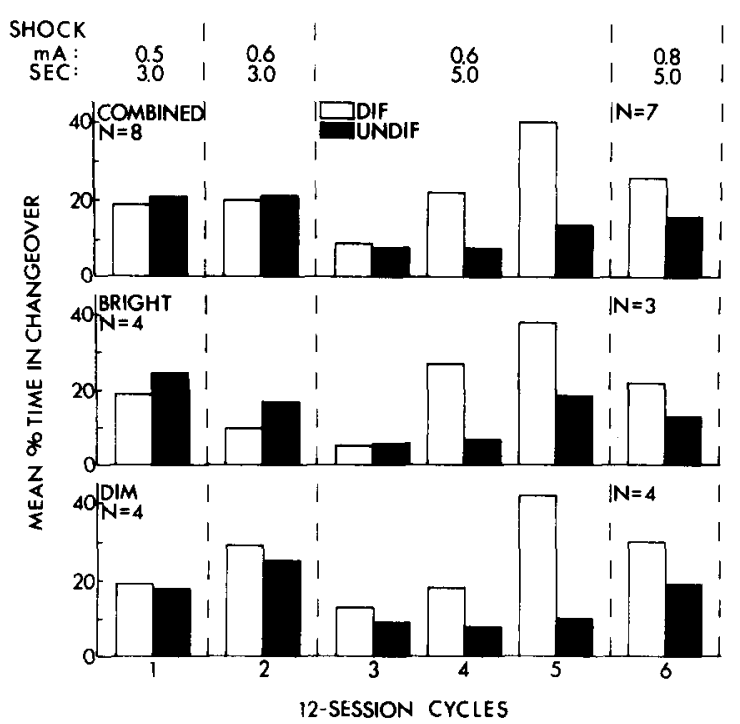

Figure 1. Mean percentage of time spent in the differentiated (DIF) and undifferentiated (UNDIF) conditions during Cycles 1-6. The intensity and duration of the longer shock stimulus was systematically increased across experimental cycles as shown at the top of the figure. The duration of the shorter shock was fixed at .75 sec throughout the experiment. The top panel presents the data collapsed over the lighting condition variable; the center and bottom panels present the data of groups that had the bright and dim illumination, respectively, as the stimulus correlated with the differentiated condition. over the last three sessions of a phase. Figure 1 presents these data for Cycles 1-6 in terms of whether changeover responding produced the differentiated or the undifferentiated condition. The results are presented both for the bright and dim correlated stimulus groups and for their combination. All of the statistical analyses reported below are based on data pooled across the shock density variable, which was not found to be a significant source of variation, either alone or in interaction with the lighting condition or the signaled condition.

As is clear from Figure 1, during Cycles 1-2 there was no preference shown for either signaled condition. However, a split-plot ANOVA based on the main factors of lighting condition and signaled condition revealed that the interaction between these two variables was significant $[\mathrm{F}(1 / 6)=6.15, \mathrm{p}<$ $.05]$; thus, the animals showed a preference for the dim correlated stimulus, irrespective of the signaled condition with which it was associated. Although a similar overall preference continued into Cycle 2, it was not statistically significant $[\mathrm{F}(1 / 6)=1.21]$.

Preference for the differentiated condition began to emerge in Cycle 3, after the duration of the long shock was increased to $5 \mathrm{sec}$. A split-plot ANOVA performed on the data of Cycles 3-5, with lighting condition, signaled condition, and cycle as the main factors revealed a significant main effect for signaled condition $[F(1 / 6)=20.99, p<.005]$, cycle $[F(2 / 12)$ $=12.31, \mathrm{p}<.005]$, as well as a Signaled Condition by Cycle interaction $[\mathrm{F}(2 / 12)=10.14, \mathrm{p}<.005]$. Referring to Figure 1, these results reflect the facts that more time was spent in the differentiated than in the undifferentiated condition and that preference for the former condition increased over Cycles 3-5. The absence of a Lighting by Signaled Condition interaction indicates that preference for the differentiated condition was of sufficient strength to offset the influence of the lighting variable on changeover behavior (cf. Safarjan \& D'Amato, 1978).

The intensity of shock was increased to its final value in Cycle 6, and the average difference in time spent in changeoever diminished, possibly as the result of "freezing" and the shock-elicited behavior which emerged in some animals. (One animal developed a terminal respiratory infection, requiring its removal from the experiment.) Nevertheless, preference for the differentiated condition continued during this cycle $[\mathrm{t}(6)=3.98, \mathrm{p}<.01]$.

As noted earlier, at the beginning of Cycle 7 a changeover delay was added and the session duration was extended to $200 \mathrm{~min}$. Figure 2 presents the mean percentage of time spent in changeover for the seven animals during Cycles 7-9. The left side of the figure contains the results of the first $100 \mathrm{~min}$ of the $200-\mathrm{min}$ session, and the right side presents the last $100 \mathrm{~min}$. Although changeover responding was less during the first $100 \mathrm{~min}$ of a session than in the second $100 \mathrm{~min}$, 


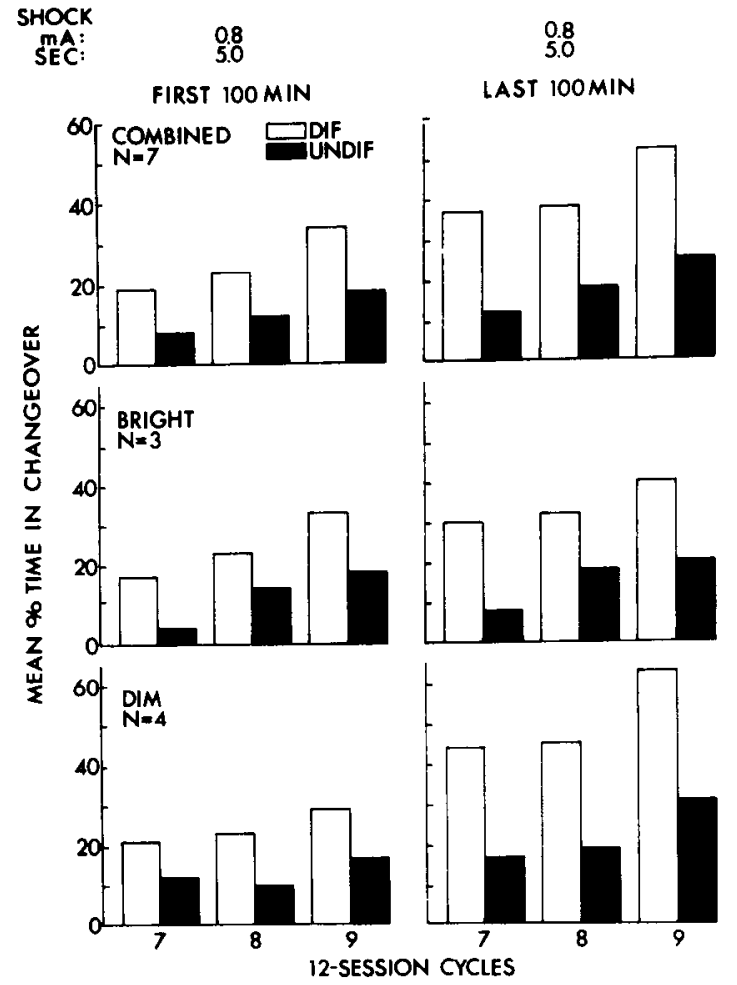

Figure 2. Mean percentage of time spent in the differentiated (DIF) and undifferentiated (UNDIF) conditions during Cycles 7-9. At the beginning of Cycle 7, session duration was extended from 100 to $200 \mathrm{~min}$ and a changeover delay was added (see text). The left and right sides of the figure present changeover behavior during the first and last $\mathbf{1 0 0}$ min of the sessions, respectively.

suggesting a "warm-up" effect, a split-plot ANOVA for unequal Ns applied to the former data revealed that the main effect of signaled condition was significant $[\mathrm{F}(1 / 5)=10.31, \mathrm{p}<.025]$. Cycle $[\mathrm{F}(2 / 10)=$ $4.74, p<.05]$ was the only other source of statistical significance. The same pattern of results emerged for the last $100 \mathrm{~min}$ of a session. Signaled condition $[F(1 / 5)=44.25, p<.005]$ and cycle $[F(2 / 10)$ $=7.87, \mathrm{p}<.01]$ were significant, but not the lighting variable or any of the interactions.

Figure 3 presents individual animal data for Cycles 7-9 (last $100 \mathrm{~min}$ ) in terms of difference scores. These scores, which were obtained by subtracting the percentage of time spent in the undifferentiated condition from the time spent in the differentiated condition, served as an index of the animal's overall preference for the differentiated condition. Although somewhat variable in extent, Figure 3 shows that preference for the differentiated condition was exhibited by all animals in all three cycles.

\section{DISCUSSION}

Before embarking on the present research, we were aware that it would not be an easy matter to demon- strate within the changeover paradigm that information about shock duration was reinforcing, even if the phenomenon were a genuine one. The differentiated and undifferentiated conditions both contain powerful reinforcers (discriminable shock-free periods), and to the same degree. Whatever control of changeover behavior might be exerted by information about shock duration is likely to be considerably weaker and less direct than that imposed by discriminable shock-free periods. Furthermore, a difficult set of discriminations is required of the animals and under circumstances not conducive to forming subtle discrimination. In spite of these handicaps, a clear and consistent preference for the differentiated condition was demonstrated in the present experiment.

An earlier pilot study, conducted under generally similar conditions as the present investigation and continued for 48 sessions (four cycles), failed to produce a preference for the differentiated condition. Although it is not possible to identify with precision the changes responsible for the emergence of the phenomenon in the present study, we suspect that a primary facilitating factor was the use of discriminably different stimuli to identify the aversive events of the differentiated and undifferentiated conditions. In the pilot study, white noise was used in both signaled conditions. Duration of the long shock may also have been a significant factor, as the long shock in the pilot experiment was only $3 \mathrm{sec}$ and preference for the differentiated condition did not emerge in the present study until the long shock was increased to $5 \mathrm{sec}$.

Marlin and Greco (Note 1) recently reported that

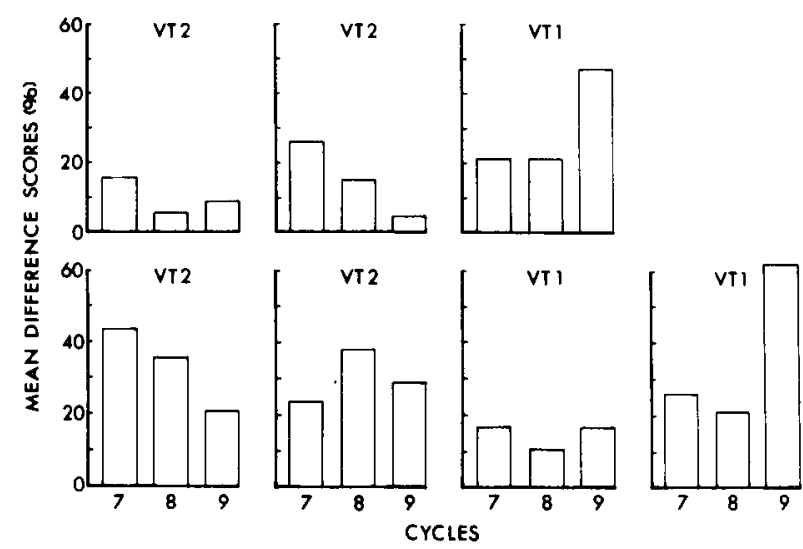

Figure 3. Individual difference scores (percent time in differentiated condition minus percent time in undifferentiated condition) for individual subjects during Cycles 7.9 (last $100 \mathrm{~min}$ ). Each bar indicates the animal's preference for the differentiated condition. Subjects in the top row had the bright level of illumination correlated with the differentiated condition; for subjects in the bottom row, the dim illumination served that function. The shock-presentation schedule (variable-time 1 or $2 \mathrm{~min}$ ) is shown for each animal. 
information about shock duration failed to reinforce shuttle behavior in their rats. There are many differences between their situation and ours, but one that may be especially significant is the fact that their animals were free to shuttle between the two compartments of the shuttlebox, which correspond to our differentiated and undifferentiated conditions. If the animals occasionally changed compartments during the delivery of long shock, discrimination of which compartment was associated with which contingency might have been impeded. It is interesting, in this connection, that with shock duration held constant at $.5 \mathrm{sec}$, a value too brief to allow shuttling during shock presentation, one group of rats did show a preference for information about shock intensity. [Like us, Marlin and Greco employed discriminably different stimuli in the two signaled conditions, which, in part, may account for their success with the shock intensity variable (cf. Freeman \& Badia, 1975)].

Our finding that information regarding shock duration is reinforcing lends itself to a number of possible interpretations. Some of these can be easily dismissed. It is not likely that the animal's preference for the differentiated condition was due to unauthorized shock avoidance or shock reduction. A related argument has been made to account for certain cases of preference for signaled shock (e.g., Biederman \& Furedy, 1976). In the present case, however, all shocks were signaled in both the differentiated and undifferentiated conditions, and if it were possible for the animal to use the shock signal as a cue to engage in responses that either avoided or attenuated the impending shock, there seems no reason why this behavior would not have occurred equally in both conditions.

A more subtle possibility is that because of the wide disparity in shock durations, the short shock was ultimately reduced to the status of an ineffective aversive stimulus so that, in essence, only a single aversive stimulus (the long shock) operated in the differentiated and undifferentiated conditions. Were this the case, the experiment could be conceptualized as providing the animal a choice between two signaled-shock conditions, one of which (the undifferentiated condition) contained extra signals. Observation of the animals, however, revealed that they consistently reacted (e.g., flinching) to the short shock, even during the terminal test sessions. But even if the preceding analysis were substantially correct, we have already pointed out that, allowed to choose between one signaled condition that contains extra signals and one that does not, rats seem not to prefer either condition (Safarjan \& D'Amato, 1977; cf. Badia et al., 1976).

With regard to the theoretical positions mentioned in the introduction, the information hypothesis obviously has little difficulty accounting for the present results. Information about shock duration reduces the animal's uncertainty about the nature of the impending shock and consequently serves to reinforce changeover behavior. The preparatory response hypothesis can also account for the results, but only at the cost of assuming that for optimal preparation different responses are required for shocks of short and long duration.

The safety-signal hypothesis seems least able to deal with the obtained results, inasmuch as the reinforcement provided by discriminable shock-free periods must, it seems, be assumed to be equal in the differentiated and undifferentiated conditions. However, there is no reason for this hypothesis to restrict itself to events that transpire during nonshock periods. It is conceivable, for example, that the aversiveness attached to the shock signals differed in the differentiated and undifferentiated conditions. In the former condition, one stimulus was paired with the short shock and a discriminatively different stimulus with the long shock. Presumably, therefore, the first stimulus was a weaker conditioned aversive stimulus than the second, and one can conceive of their overall aversiveness as being reflected by the average aversiveness of the two. In the undifferentiated condition, the same stimulus signaled short and long shocks, thus developing a conditioned aversiveness of an intensity lying between that of the two signals used in the differentiated condition. However, this value need not be identical to that produced by the average of the two shock stimuli of the differentiated condition. Indeed, it can be deduced from the WagnerRescorla conditioning model (Wagner \& Rescorla, 1972, pp. 301-336) that the aversiveness associated with the stimulus of the undifferentiated condition will be greater than the mean aversiveness attached to the two stimuli of the differentiated condition.

Consequently, although the finding that information about the nature of an impending shock can serve as a reinforcer is interesting in its own right, it apparently cannot serve to differentiate critically among the preparatory response, information, and safety-signal hypotheses. In part, this reflects the overlap among the three positions. The preparatory response hypothesis may be viewed as one specification of the way in which information gains its reinforcing function. And obviously, without appropriate information an animal could not engage in preparatory responses or classify specific events as "safe" or "unsafe." Beyond the issue of conceptual overlap, however, is the question of specificity. None of the theories is stated with the precision that makes the impact of relevant empirical results unambiguous. If, for example, it turned out that information about shock duration had no effect on changeover behavior, the preparatory response and safety-signal hypotheses probably could have accommodated this outcome just as easily as the positive result that was obtained. 


\section{REFERENCE NOTE}

1. Marlin, N. A., \& Greco, C. Preference for information concerning intensity of unmodifiable tailshock. Paper presented at the Eastern Psychological Association meeting, Washington, D.C., April 1978.

\section{REFERENCES}

BAdia, P., \& Culbertson, S. The relative aversiveness of signalled vs unsignalled escapable and inescapable shock. Joumal of the Experimental Analysis of Behavior, 1972, 17, 463-471.

Badia, P., Harsh, J., Coker, C. C., \& Abrott, B. Choice and the dependability of stimuli that predict shock and safety. Journal of the Experimental Analysis of Behavior, 1976, 26, 95-111.

BERLYNE, D. E. Conflict, arousal, and curiosity. New York: McGraw-Hill, 1960.

Biederman, G. B., \& Furedy, J. J. Preference for signaled shock in rats?: Instrumentation and methodological errors in the archival literature. The Psychological Record, 1976, 26, 501-514.

Catania, A. C., \& Reynolds, G. S. A quantitative analysis of the responding maintained by interval schedules of reinforcement. Journal of the Experimental Analysis of Behavior, 1968, 11, 327-383.

FREEMAN, J., \& BADIA, P. Do rats prefer information about shock intensity? Bulletin of the Psychonomic Society, 1975, 6, 75-78.

HARSH, J., \& BADIA, P. A temporal parameter influencing choice between signaled and unsignaled shock schedules. Journal of the Experimental Analysis of Behavior, 1976, 25, 327.333.
Hy mowirz, N. The suppression of responding during signalled and unsignalled shock. Psychological Bulletin, in press.

LOCKARD, J. S. Choice of a warning signal or no warning signal in an unavoidable shock situation. Joumal of Comparative and Physiological Psychology, 1963, 56, 526-530.

Perkins, C. C., JR. An analysis of the concept of reinforcement. Psychological Review, 1968, 75, 155-172.

Perkins, C. C., Jr., Seymann, R. G., Levis, D. J., \& Spencer, H. R., JR. Factors affecting preference for signal-shock over shock-signal. Journal of Experimental Psychology, 1966, 72, 190-196.

Safarjan, W. R., \& D'Amato, M. R. Preference and information about the time and the occurrence of shock delivery. Bulletin of the Psychonomic Society, 1977, 10, 355-357.

SAfarjan, W. R., \& D'Amato, M. R. Variables affecting preference for signaled shock in a symmetrical changeover design. Learning and Motivation, 1978, 9, 314-331.

SEligman, M. E. P., \& BiniK, Y. M. The safety signal hypothesis. In H. Davis and H. M. B. Hurwitz (Eds.), Operant-Pavlovian interactions. Hillsdale, N!.J: Erlbaum, 1977.

W AGNER, A. R., \& ResCorla, R. A. Inhibition in Pavlovian conditioning: Application of a theory. In R. A. Boakes \& M. S. Halliday (Eds.), Inhibition and learning. New York: Academic Press, 1972.

(Received for publication April 14, 1978; revision accepted July 21,1978 .) 